\title{
ON NUCLEOLAR DNA REPLICATION IN TETRAHYMENA PYRIFORMIS GL-8: AN ELECTRON MICROSCOPE AUTORADIOGRAPHIC STUDY OF HEAT SYNCHRONIZED AND EXPONENTIALLY MULTIPLYING CELLS
}

\author{
by \\ JYTTE R. NILSSON and ERIK ZEUTHEN* \\ Institute of General Zoology, University of Copenhagen, \\ Universitetsparken 15, DK-2100 Copenhagen $\emptyset$ \\ and \\ Biological Institute of the Carlsberg Foundation, \\ Tagensvej 16, DK-2200 Copenhagen N
}

Keywords: Nucleolar DNA replication, Tetrahymena pyriformis, EM autoradiography, cell cycle, synchronized cells

\begin{abstract}
Replication of nucleolar DNA in Tetrahymena was studied, after a 10-min labelling with tritiated thymidine, in synchronized cells (»one heat shock per generation«) around the synchronous cell division, and in cells from an exponentially multiplying culture. The purpose was to investigate the timing of replication of the ribosomal RNA genes, since there is a controversy in the literature on this point. Replication of the ribosomal RNA genes was determined in electron microscope autoradiograms as the presence of silver grains above the peripherally located nucleoli in the macronucleus; the degree of labelling within each nucleolus cannot be determined since the size of an activated silver bromide crystal corresponds to the diameter of a nucleolus. Our results, expressed as the percentage of cells showing labelling of the nucleolar region, revealed a significant fall during the synchronous cell division, thus indicating that replication of nucleolar DNA does not take place during cell division. Another finding was that cells active in DNA synthesis (S-phase) had a higher percentage of labelled nucleoli than that found in cells at any other stage. No difference in replication of the nucleolar DNA was found in heat synchronized cells and in cells from exponentially multiplying populations, apart from the absence of a $\mathrm{G}_{1}$-stage in the former cells. Our conclusion is that the ribosomal RNA genes are replicated throughout the cell cycle except during division and that cells in the S-phase may have an intensified rate of replication of these genes.
\end{abstract}

*Deceased on January 10th, 1980.

Abbreviations: $\mathrm{EH}=$ end of heat shock; $\mathrm{EM}=$ electron microscope; $\mathrm{LM}=$ light microscope. 


\section{INTRODUCTION}

The ribosomal RNA genes are situated in the nucleolar organizer of the peripherally located nucleoli in the macronucleus of Tetrahymena (e.g. (6)). These genes are palindromic molecules $(11,17,9,7)$ which have been studied extensively. The ribosomal genes are extrachromosomal, detached from the bulk of the macronuclear chromatin $(12,15)$, and in Tetrahymena strains capable of conjugation a preferential amplification of these genes occurs early during the sexual cycle (25). The macronucleus of Tetrahymena contains 500-1,000 nucleoli (22) each containing one nucleolar organizer with about 10 ribosomal RNA genes.

Several studies have revealed correlation between the synthesis of ribosomes and the appearance of the nucleolar organization in Tetrahymena. Thus, a high rate of production of ribosomes is correlated with the presence of numerous, small nucleoli located peripherally in the macronucleus (19), whereas little or no synthesis occurs in cells in which the nucleoli have aggregated into large fusion bodies, as for example in starved cells. Such aggregation of the nucleoli is not correlated with loss of ribosomal RNA genes (10).

A point of controversy in the literature is the timing of replication of these ribosomal RNA genes in Tetrahymena. Thus, replication of the nucleolar DNA has been reported to occur exclusively during a defined stage of the cell cycle (16) such as during the $\mathrm{G}_{2}$-phase (6), during the $\mathrm{G}_{1}$-phase $(13,14)$, and during the early S-phase (1); however, the event has also been reported to occur throughout the cell cycle with a possible stop during cell division (24). In all these studies the culture conditions, as well as the method of determination of the replicated DNA, differ.

In the present study we used Tetrahymena pyriformis from heat synchronized and from exponentially multiplying populations. The cells were exposed to tritiated thymidine for a short period, after which localization of labelled material in the nucleolar region was determined by electron microscope autoradiography. The purpose was to analyse the events in individual cells in relation to their stage in the cell cycle.

\section{MATERIAL AND METHODS}

Tetrahymena pyriformis GL-8 (4) was grown axenically at $28{ }^{\circ} \mathrm{C}$ in $2 \%$ proteose-peptone enriched with $0.1 \%$ liver extract and inorganic salts (PP-medium) (27). The cells were synchronized with respect to cell division using the sone heat shock per generation « method (28), i.e. the cells were exposed to $34^{\circ} \mathrm{C}$ for 20 min (heat shock) at intervals spaced $160 \mathrm{~min}$ apart. After the 6. heat shock the cells were exposed to tritiated thymidine (Amersham, Radiochemical Centre, TRA 120) at a specific activity of 25 $\mu \mathrm{Ci} \cdot \mathrm{ml}^{-1}$, for $10 \mathrm{~min}$ at different intervals during the culture cycle. The exposed cell samples were prepared for light microscope autoradiography using K5 Ilford emulsion and the dipping method (3), simultaneously with preparation for electron microscope (EM) autoradiography, as described below. A sample of exponentially multiplying cells was treated in a manner similar to that of the heat synchronized cells.

For electron microscopy the cells, after the exposure to the nucleoside, were fixed for $10 \mathrm{~min}$ in $2 \%$ glutaraldehyde $(\mathrm{v} / \mathrm{v})$ in $0.1 \mathrm{M}$-cacodylate buffer $(\mathrm{pH} \mathrm{7.4)}$ and, after a brief wash in the buffer, for $1 \mathrm{~h}$ in $1 \%$ osmium tetroxide in the same buffer. Dehydration was carried out in a graded series of ethanols and finally in propylene oxide before embedding in epon according to $\mathrm{J}$. H. LuFT (18). Golden sections were cut on an LKB Ultratome and mounted on grids with carbon-coated collodin films. The sections were contrasted for $1 \mathrm{~h}$ with $1 \%$ aqueous uranyl acetate and coated with a thin layer of carbon before application of L4 Ilford emulsion in a monolayer using the »loop" method (5), as described previously (21). The autoradiograms were developed after 6 weeks of exposure in Microdol X: the sections were contrasted with lead hydroxide for $10 \mathrm{~min}$ (26) before examination in a Zeiss EM9 electron microscope. Micrographs were taken at primary magnifications of $1,800 \times-6,000 \times$.

\section{RESULTS}

\subsection{Exponentially multiplying cells}

The cell density of the population was 80,000 cells $\cdot \mathrm{ml}^{-1}$, and the generation time $160 \mathrm{~min}$, at the time of the $10-\mathrm{min}$ exposure to tritiated 


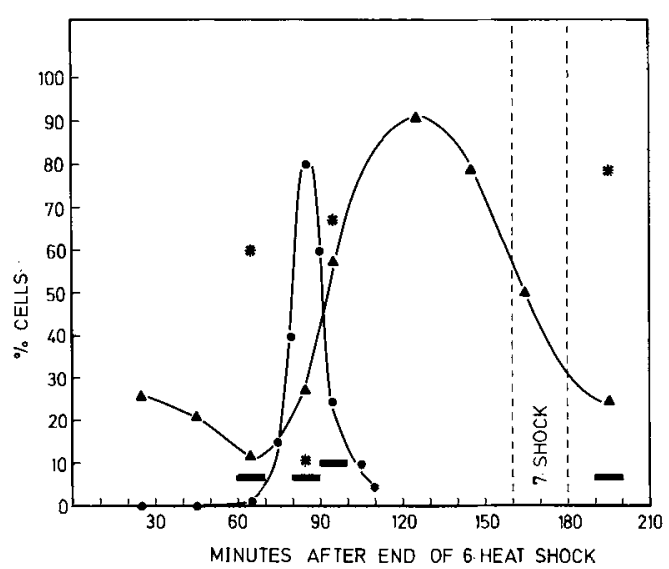

Figure 1. Summary of the light microscopic (LM) and electron microscopic (EM) observations on the heat synchronized population of Tetrahymena.

( $)$ : In division, $\boldsymbol{\Delta}$ : in S-phase, ${ }^{*}$ : with labelled nucleoli, $\square$, EM-sample.) LM: The percentage of cells (ordinate) in cell division and in DNA synthesis with time after the end of the 6th heat shock (abcissa); the timing of the 7 th heat shock is indicated by the column. EM: The asterisks indicate the percentage of cells with some labelling of the nucleolar region, i.e., having replicated their nucleolar DNA. The horizontal hars indicate the time of exposure of the EMsamples to tritiated thymidine.

thymidine, hence the labelling period represents $1 / 10$ of the cell cycle time.

The electron microscope (EM) autoradiograms included sections of 7 cells containing the macronucleus. In 5 cells $(71 \%)$ silver grains were present above the macronuclear chromatin, i.e. the cells were in the S-phase; on the average $10 \%$ of the nucleoli were labelled (ranging from $6 \%$ to $14 \%$ ). This determination of nucleolar labelling refers to the finding of one silver grain (curly configuration) above a nucleolus; the curly configuration of the silver grain has an extension corresponding to the diameter of the nucleolus. The macronucleus of a typical cell in DNA synthesis is shown in Figure 2, where also the typical arrangement of the numerous small, peripherally located nucleoli is shown. A late $\mathrm{G}_{2^{-}}$ phase cell (14\%) with the macronuclear chromatin arranged in "subnuclei« (20) was unlabelled, whereas a cell in early $\mathrm{G}_{2}$-phase (14\%) had $4 \%$ of the nucleoli labelled. These findings are in good agreement with a previous report (21) where 23 cells were analysed under corresponding growth conditions; here cells active in DNA synthesis had $10 \%$ of their nucleoli labelled and $23 \%$ of all cells were unlabelled.

\subsection{Heat synchronized cells}

The population received 6 heat shocks after which the cell density was 25,000 cells $\cdot \mathrm{ml}^{-1}$. In the present experiment the actual increase in cell density was $70 \%$ after the synchronous cell division which is somewhat lower than that generally achieved in this system (28). The percentage of cells in division (figure 8-shaped) is plotted with time after the end of the 6 . heat shock (EH) in Figure 1, where also the percentage of cells in the S-phase (light microscope (LM) autoradiography) is shown.

For EM autoradiography 4 cell samples were labelled for $10 \mathrm{~min}$ with tritiated thymidine added at $60 \mathrm{~min} \mathrm{EH}, 80 \mathrm{~min} \mathrm{EH}, 90 \mathrm{~min} \mathrm{EH}$, and $190 \mathrm{~min} \mathrm{EH}$ (after having received the 7. heat shock at 160-180 min EH), respectively; these intervals are indicated on Figure 1 by horizontal bars. The labelling period corresponds to $1 / 18$ of the cell cycle time, since the synchronous cell divisions in the system are spaced $180 \mathrm{~min}$ apart. The observations of the 4 samples will be described separately.

\subsubsection{Labelling during $60-70 \mathrm{~min} \mathrm{EH}$}

One cell $(10 \%)$ of the 10 cells examined contained several silver grains above the macronuclear chromatin, a finding which is in agreement with the $12 \%$ of the cells observed to be in the S-phase by LM autoradiography (Figure 1); in this cell $16 \%$ of the nucleoli were labelled. The remaining 9 cells $(90 \%)$ were all in the early $\mathrm{G}_{2}$-phase as based on the configuration of the macronuclear chromatin $(20,21)$, as well as on the presence of an oral primordium (Figure 6 ) in sections of 3 cells. No nucleolar labelling was seen in 4 of these cells (Figure 5), whereas 5 cells showed a $2 \%$ to $5 \%$ labelling of nucleoli (Figure 7). A so-called RNA-body $(8,23)$ was observed in 2 cells $(20 \%)$. The result of these observations was that $60 \%$ of all cells showed some nucleolar labelling (Figure 1). 

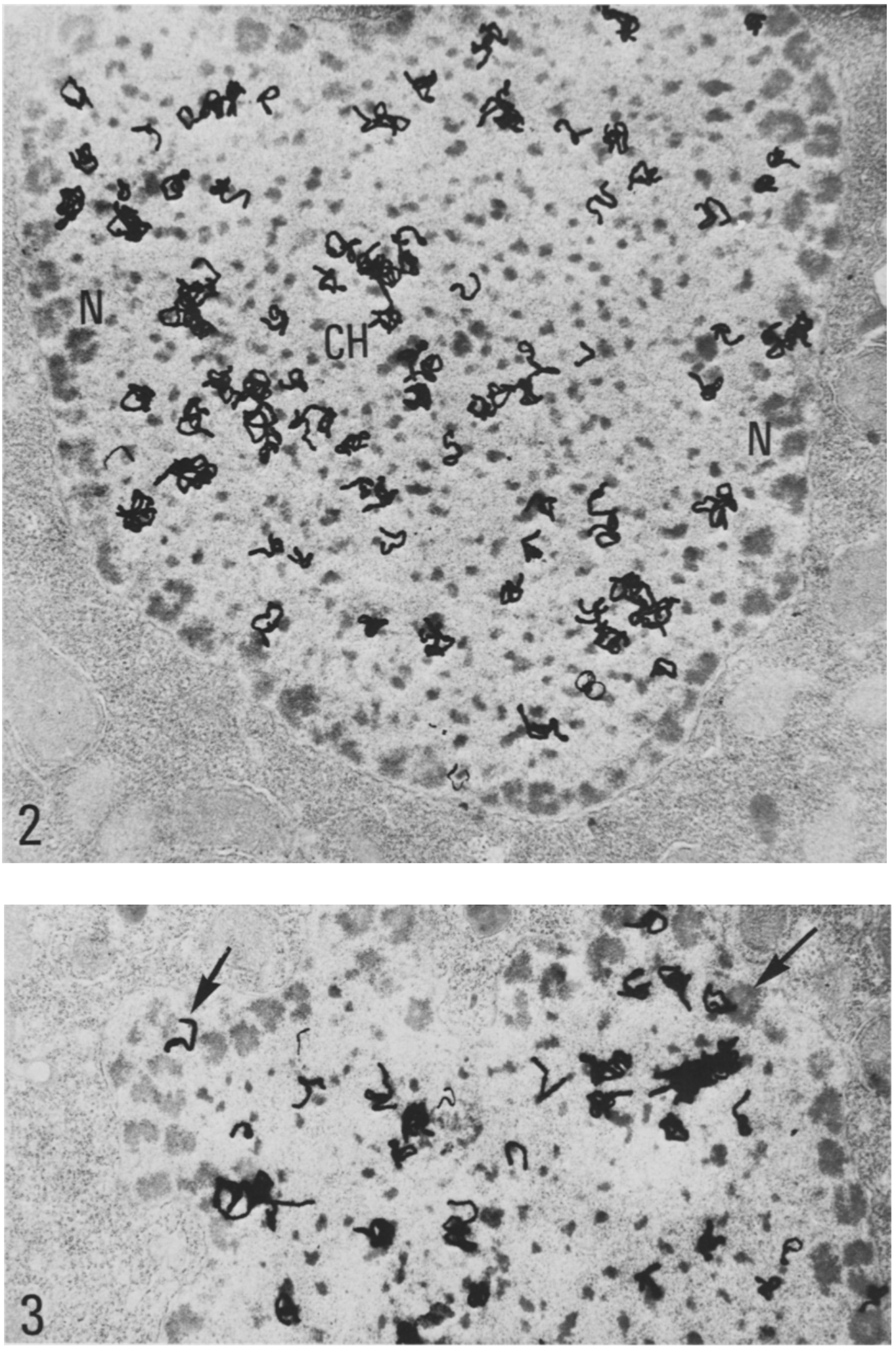

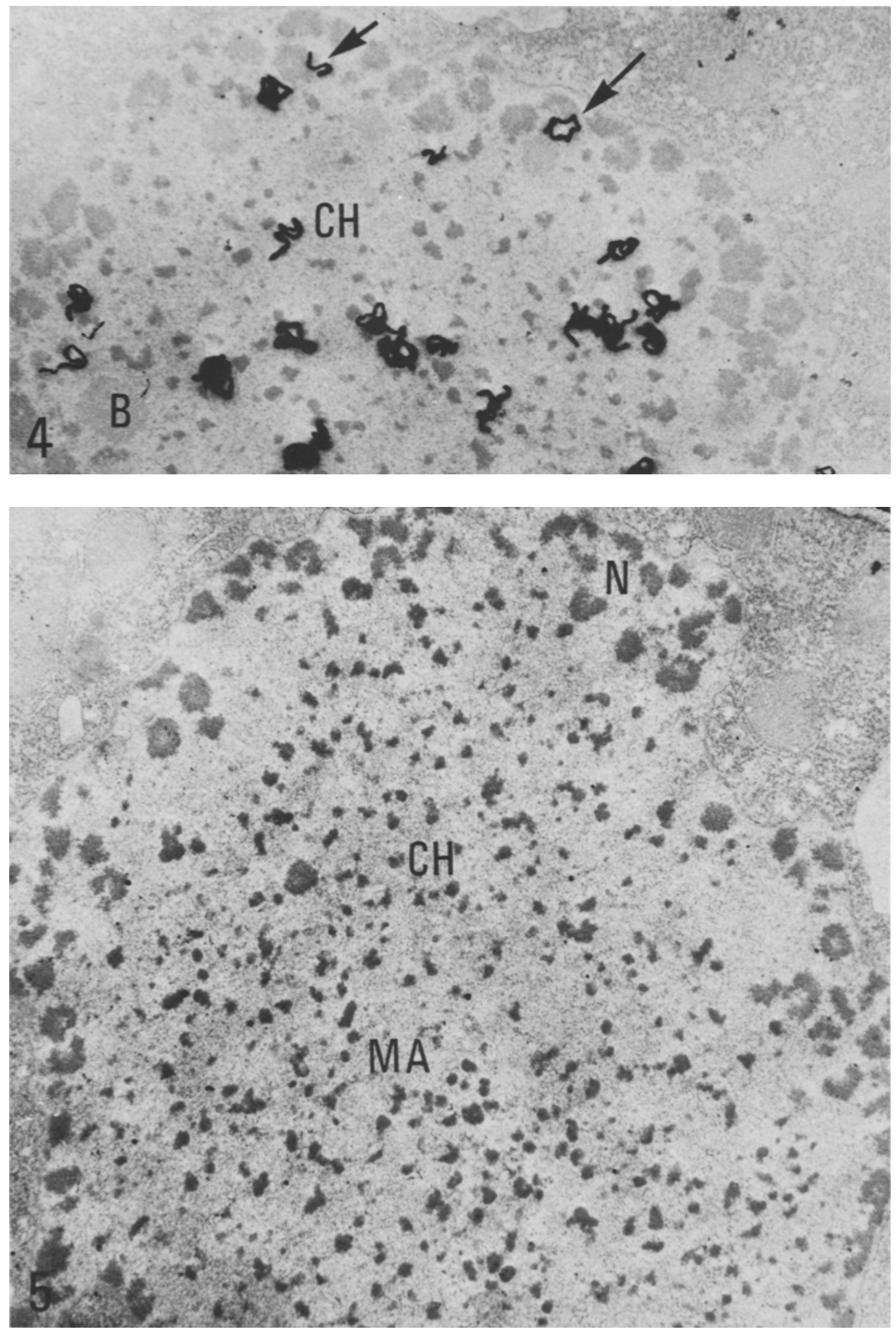

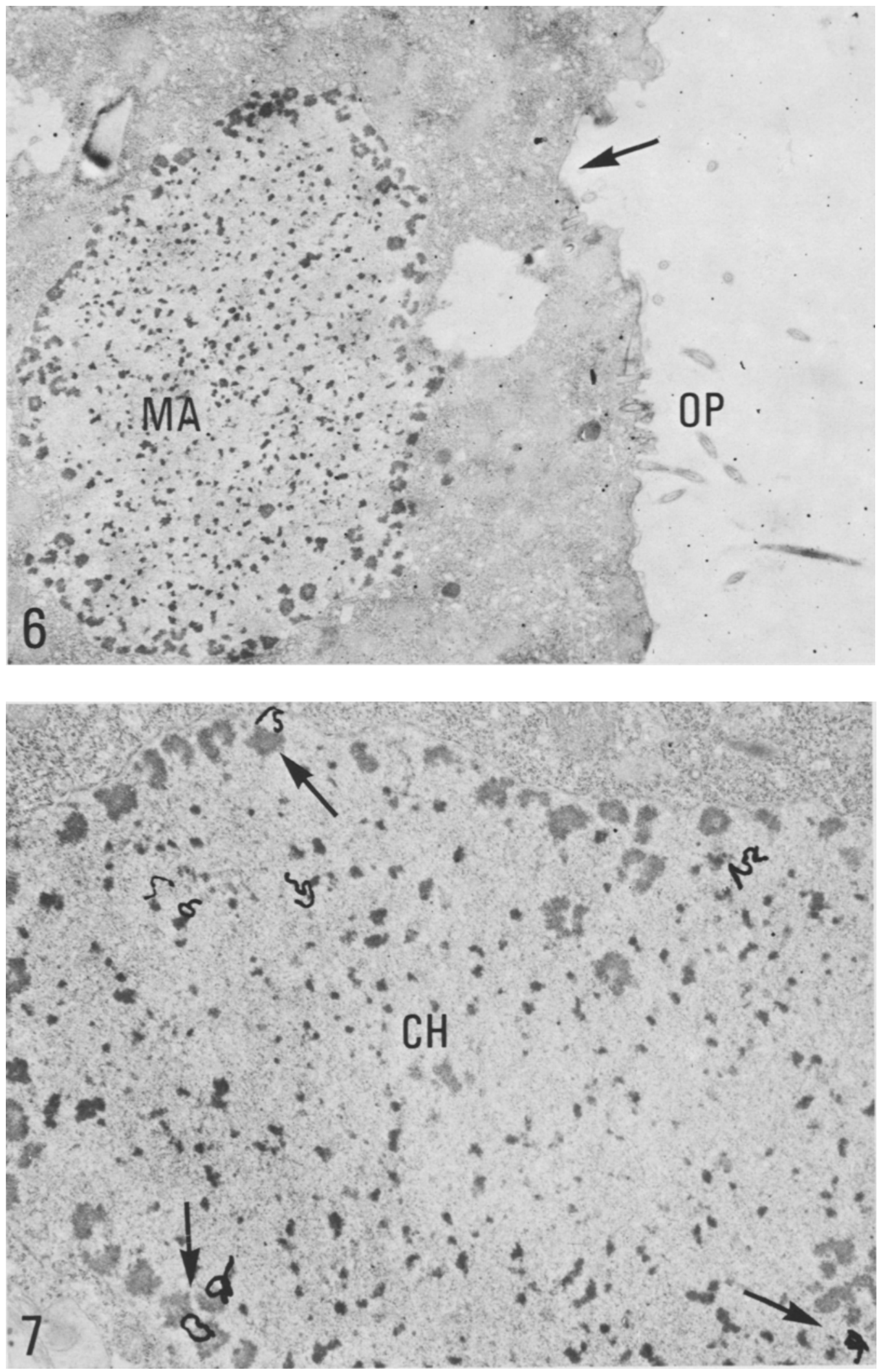

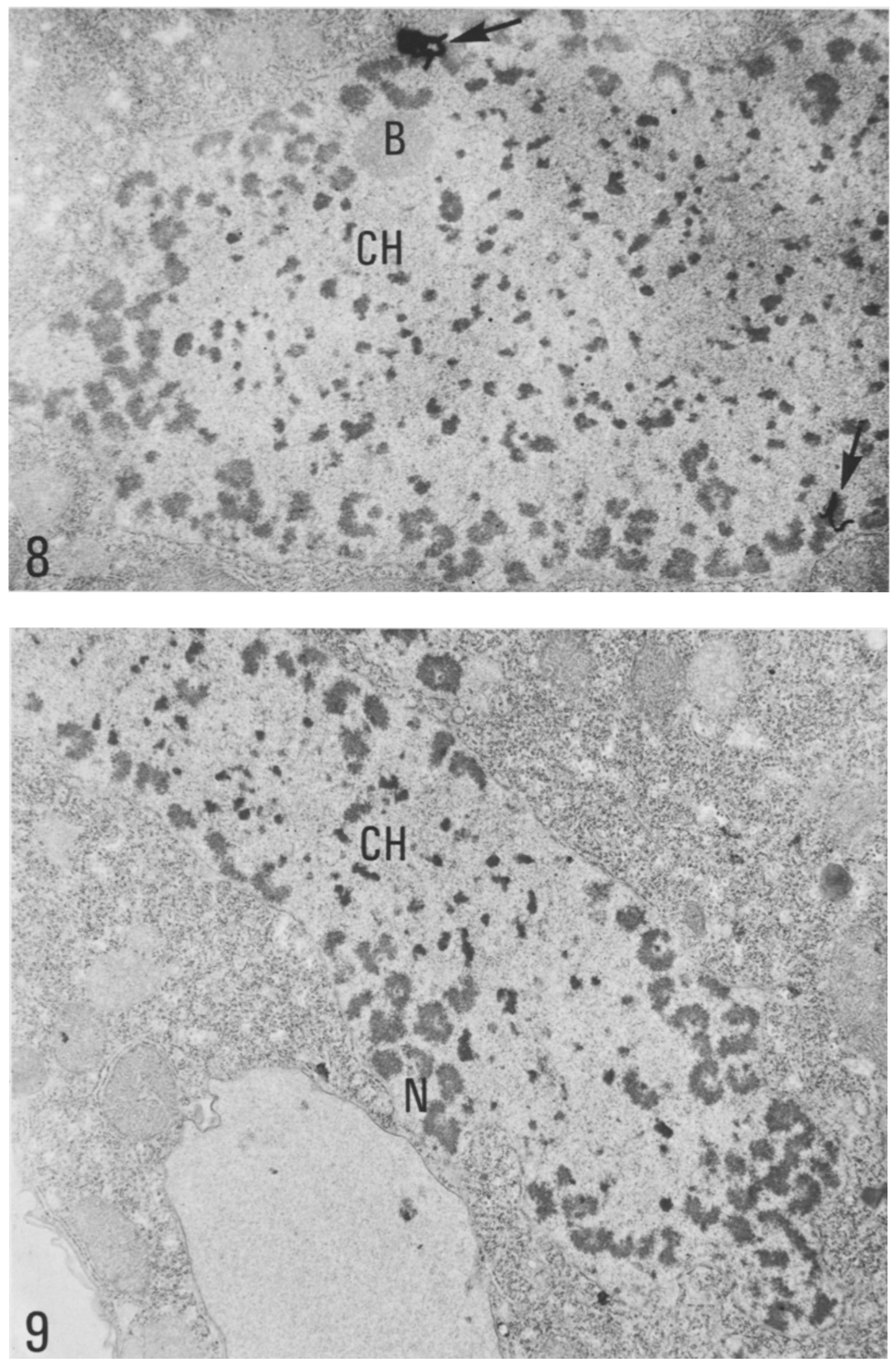
Figures 2-9. Electron microscope autoradiograms of Tetrahymena exposed for 10-min to tritiated thymidine.

The developed silver grains have a curly configuration. Magnification: 15,000 times, apart from Figure 5 (7,200 times).

Figure 2. The macronucleus of a cell from the exponentially multiplying population.

The cell is in the S-phase, as indicated by the presence of several silver grains above the chromatin region $(\mathrm{CH})$. Silver grains are also present above the nucleoli $(\mathrm{N})$ indicating that replication of the nucleolar DNA has occurred.

Figure 3. Part of the macronucleus of a synchronized cell (sample 90-100 min EH).

The cell is in the S-phase. Silver grains are present above the nucleoli (arrows) indicating that replication of the nucleolar DNA has taken place. Note that the nucleolar organization is the same as that found in exponentially multiplying cells (see Figure 2).

Figure 4. Part of the macronucleus of a synchronized cell after the 7. heat shock (sample 190-200 min EH, see Figure 1).

The cell is in the S-phase with silver grains above the chromatin region $(\mathrm{CH})$ and above the nucleoli (arrows). Note the somewhat "fluffy « appearance of the nucleoli as a result of the 7. heat shock. An RNA-body (B) is seen.

Figure 5. Macronucleus (MA) of a cell in $\mathrm{G}_{2}$-phase (60-70 min $\mathrm{EH}$ ).

No incorporation of tritiated thymidine has occurred in the chromatin $(\mathrm{CH})$ or the nucleolar $(\mathrm{N})$ regions, thus this cell has not replicated the nucleolar DNA during the exposure. A lower magnification of this cell is shown in Figure 6.

Figure 6. A low magnification of the $\mathrm{G}_{2}$-phase cell shown in previous figure (60-70 $\mathrm{min} \mathrm{EH}$ ).

No labelling is found in the macronucleus (Figure 5). The indentation (arrow) represents the early division furrow and below this the section passes through the oral primordium (OP).

Figure 7. $\mathrm{A} \mathrm{G}_{2}$-phase cell with a few silver grains above the chromatin region $(\mathrm{CH})$ and with labelling in the nucleolar region (arrows).

From a cell 60-70 min EH. Primarily the nucleolar region is labelled.

Figure 8. A G2-phase nucleus from a cell 90-100 min EH.

No labelling is present above the macronuclear chromatin $(\mathrm{CH})$ but only above the nucleolar region (arrows), thus indicating that only replication of the ribosomal RNA genes has occurred. An RNA-body (B) is shown.

Figure 9. Part of a dividing (elongated) macronucleus is shown from a cell 90-100 min EH.

No labelling of either the chromatin $(\mathrm{CH})$ or the nucleolar $(\mathrm{N})$ region is seen, thus indicating that no replication of the nucleolar DNA takes place during cell division.

\subsubsection{Labelling during $80-90 \mathrm{~min} E H$}

This interval includes the maximum of dividing cells at $85 \mathrm{~min}$ EH (Figure 1). The percentage of cells in division (figure 8-shaped) decreases from $80 \%$ to $60 \%$, and the percentage of cells in the S-phase increases from $15 \%$ to 27\% (Figure 1).

Of the 9 cells examined in the EM autoradiograms, one cell $(11 \%)$ was active in DNA synthesis. This cell most likely represents a young daughter cell as judged by its relatively small size and roundish shape; $18 \%$ of its nucleoli were labelled. The configuration of the macronuclear chromatin in the remaining 8 cells was typical of $\mathrm{G}_{2}$-phase cells. In two of these cells ( $22 \%)$ a single silver grain was found above the chromatin, whereas no labelling was observed in the 6 cells (67\%); an RNA-body was observed in one cell (11\%). $11 \%$ of all cells had labelled nucleoli (Figure 1).

\subsubsection{Labelling during 90-100 $\mathrm{min}$ EH}

The percentage of dividing cells decreases from $60 \%$ to $10 \%$, thus the number of cells increases maximally during this interval. The percentage of cells in the S-phase increases from $27 \%$ to $58 \%$ (Figure 1 ). 
Of the 12 cells examined in the EM autoradiograms, 3 cells ( $25 \%$ ) had many silver grains above the chromatin region (Figure 3 ). The percentage of labelled nucleoli in these cells was $5 \%, 9 \%$, and $13 \%$, respectively. The macronucleus in 5 cells $(42 \%)$ was roundish or irregular in shape and their chromatin configuration indicated that the cells were in the $\mathrm{G}_{2-}$ phase; 3 of the cells had $3 \%$ of their nucleoli labelled (Figure 8), whereas no nucleolar labelling was observed in 2 cells. In 4 cells (33\%) the macronucleus was elongated, as typical for the late division stage, and no nucleolar labelling was observed (Figure 9). An RNA-body was observed in a $\mathrm{G}_{2}$-phase cell ( $8 \%$ ). $67 \%$ of all cells had labelled nucleoli (Figure 1).

\subsubsection{Labelling during "190-200 min EH"}

Since the cells received the 7 . heat shock at 160-180 min EH, this cell sample represents the events at 10-20 min EH. The percentage of cells in the S-phase was 25\% (Figure 1).

In all 9 cells examined in the EM autoradiograms the nucleoli had a "fluffy « appearance, a typical effect of the increased temperature during the heat shock (23); however, the nucleoli are not aggregated (Figure 4). Four cells (44\%) were in the S-phase with several grains above the macronuclear chromatin; the percentage of labelled nucleoli ranged from $10 \%$ to $17 \%$. Three cells $(33 \%)$ had few grains above the chromatin region, whereas 2 cells $(22 \%)$ were unlabelled in this region. In 3 cells the nucleolar labelling was $2 \%, 6 \%$, and $7 \%$, respectively, and 2 cells were unlabelled. An RNA-body was observed in 1 cell (11\%). 78\% of all cells had labelled nucleoli (Figure 1).

\subsubsection{Summary of the results on synchronized cells}

Our data have revealed that not all cells have labelled material in the nucleolar region. When expressed as the percentage of cells with any label in the region, there is a clear drop during the maximum of the synchronous division, as indicated by asterisks on Figure 1. Furthermore, our observations have revealed that cells in the Sphase have a higher percentage of their nucleoli labelled than that found in cells in any other stage. These findings also apply to cells from exponentially multiplying populations.

\section{DISCUSSION}

The slight imperfection of synchrony in the heat synchronized population of Tetrahymena was not significant for the present analysis of single cells, because the different cell stages are easily identified on the basis of their fine structure (21). Although there may be some difficulty in distinguishing between $\mathrm{G}_{1^{-}}$and $\mathrm{G}_{2}$ stage cells in some sections, this uncertainty does not arise with heat synchronized cells in which the $\mathrm{G}_{1}$-stage is absent (2). The nucleolar organization in the cells synchronized by the wone heat shock per generation « method (28) is the same as that of exponentially multiplying cells with numerous small nucleoli, thus without the nucleolar aggregation seen in cells synchronized by sthe multiple heat shock «method (23).

Our observations indicated that replication of the ribosomal RNA genes occurs throughout the major part of the cell cycle, except during cell division; this finding applies to both heat synchronized and exponentially multiplying cells. The stop in replication of these genes lasts for something between $1 / 10$ and $1 / y$ of the cell cycle time, since after a $10-\mathrm{min}$ exposure to tritiated thymidine several cells are unlabelled in the nucleolar region as shown in the present study, whereas after a 20 -min exposure to the nucleoside all 50 cells, analysed in a previous study (24), have labelled nucleoli. In the latter study, a stop for nucleolar replication during cell division was suggested (as mentioned in the Introduction). This has been confirmed in the present work.

The question which arises is: to what extent do our findings relate to the divergent findings on the timing of the replication of the ribosomal RNA genes in Tetrahymena? Firstly, using the same method of synchronization as in the present study H. A. ANDERSEN and J. ENGBERG (1) found a sharp increase in the amount of newly replicated DNA that hybridized with ribosomal RNA immediately after the synchronous division as the cells enter the S-phase. Our observations are in accordance with the assumption of these authors of an intensive replication of the ribosomal RNA genes during the early Sphase of synchrcnized cells, since we find a sharp increase in the number of cells incorporating thymidine into the nucleolar region at this time, and since cells in the S-phase have more nucleoli 
labelled than cells in other stages. However, our method is not sensitive enough to reveal a variation in the degree of labelling of individual nucleoli, because the size of each silver bromide crystal in a monolayer emulsion corresponds to that of a nucleolus, thus a crystal giving rise to the curly structure of the silver grain may have been activated by disintegrations from few or many labelled nucleotides in a single nucleolar organizer. Therefore, from the autoradiographic evidence we cannot exclude that cells in the early stage of the S-phase have a much higher rate of replication of nucleolar DNA such as shown by the more sensitive biochemical method. However, the replication event does not occur exclusively during the S-phase in the synchronized cells as shown in Figure 1.

Secondly, in another study (14) replication of the nucleolar DNA has been reported as a $\mathrm{G}_{1}$ phase event in Tetrahymena transferred to the growth medium and to continous labelling with tritiated thymidine after a 24-h starvation period. The cells were labelled in the nucleolar region before any labelling of the macronuclear chromatin was seen and the biochemical analyses confirmed that this early replication was correlated with an increased amount of ribosomal RNA genes in the cells. Cells starved for $24 \mathrm{~h}$ are small due to extensive autophagy and thereby deprived of part of their ribosomes. To restore their normal cell size and their further progress through the cell cycle, these cells initiate a high rate of protein synthesis for which new ribosomes are needed. Furthermore, 24-h starved cells have $30 \%-40 \%$ fewer ribosomal genes than cells from exponentially multiplying cultures (10), hence it is not surprising that a selective replication of the genes occurs during the nutritional upheaval upon transfer to the growth medium, especially since $G_{1}$-cells are capable of incorporating thymidine into the nucleolar region (24).

Thirdly, replication of the nucleolar DNA as a $\mathrm{G}_{2}$-event was reported by $\mathrm{R}$. CHARRET (6) using a micronucleate strain of Tetrahymena with a generation time of $6 \mathrm{~h}$. After a 2-h labelling period with tritiated thymidine a cell was found with two labelled micronuclei and a macronucleus labelled only above the nucleolar region; the finding was interpreted as restricting the replication of nucleolar DNA to the $\mathrm{G}_{2}$-phase. How- ever, only a few nucleoli are labelled in this particular cell (Figure 9 in (6)), although the cell has been labelled for $1 / 3$ of the cell cycle and with a concentration of labelled nucleoside that is four times higher than that used in the present study. This causes us to doubt the assumption that the event is confined exclusively to the $\mathrm{G}_{2}$-phase.

The conclusion of the present study is that replication of the ribosomal RNA genes in Tetrahymena occurs throughout the cell cycle with a stop during cell division. Our results are also compatible with the biochemists' assumption (1) of an intensification of replication during the S-phase. Since the replication of these genes is under a control separate from that of the bulk macronuclear DNA, the intensity of this replication may be shifted to a particular cell stage under different nutritional conditions.

\section{ACKNOWLEDGEMENTS}

The authors wish to thank Mrs. Karen MEILvang and Mrs. Helga Langelo Sørensen most gratefully for excellent technical assistance. The financial support of the Carlsberg Foundation to JytTE R. NiLsson is gratefully acknowledged.

\section{REFERENCES}

1. Andersen, H. A. \& J. Engberg: Timing of the ribosomal gene replication in Tetrahymena pyriformis. Exp. Cell Res. 92, 159-163 (1975)

2. Andersen, H. A., L. Rasmussen \& E. Zeuthen Cell division and DNA replication in synchronous Tetrahymena cultures. Current Topics in Microbiology and Immunology 72, 1-20 (1975)

3. Bernstein, E. \& E. Zeuthen: The relationship of RNA synthesis to temperature as an inducer of synchronous division. C. R. Trav. Lab. Carlsberg 35, 501-517 (1966)

4. Borden, D., G. S. Whitt \& D. L. Nanney: Electrophoretical characterization of classical Tetrahymena pyriformis strains. J. Protozool. 20, 693-700 (1973)

5. Caro, L. G.: A common source of difficulty in high-resolution autoradiography. J. Cel! Biol. 41, 918-919 (1969)

6. Charret, R.: L'ADN nucléolaire chez Tetrahymena pyriformis: chronologie de sa réplication Exp. Cell Res. 54, 353-361 (1969)

7. DiN, N. \& J. ENGBERG: Extrachromosomal ribosomal RNA genes in Tetrahymena. Struc- 
ture and evolution. J. Mol. Biol. 134, 555-574 (1979)

8. Elliot, A. M., J. R. Kennedy, Jr. \& I. J. BaK: Macronuclear events in synchronously dividing Tetrahymena pyriformis. J. Cell Biol. 12, 515531 (1962)

9. Engberg, J. \& H. Klenow: Palindromic arrangement of specific genes in lower eukaryotes. Trends in Biochemical Sciences 2, 183-185 (1977)

10. Engberg, J. \& R. E. Pearlman: The amount of ribosomal RNA genes in Tetrahymena pyriformis in different physiological states. Eur. Biochem. 26, 393-400 (1972)

11. Engberg, J., P. Andersson, V. Leick \& J. ColLINS: Free ribosomal DNA molecules from Tetrahymena pyriformis GL are giant palindromes. J. Mol. Biol. 104, 455-470 (1976)

12. Engberg, J., G. Christiansen \& V. Leick: Autonomous rDNA molecules containing single copies of the ribosomal RNA genes. Biochem. Biophys. Res. Communications 59, 1356-1365 (1974)

13. Engberg, J., D. Mowat \& R. E. Pearlman: Preferential replication of the ribosomal RNA genes during a nutritional shift-up in Tetrahymena pyriformis. Biochim. Biophys. Acta 272, 312-320 (1972)

14. Engberg, J., J. R. Nilsson, R. E. Pearlman \& $V$. LEICK: Induction of nucleolar and mitochondrial DNA replication in Tetrahymena pyriformis. Proc. Nat. Acad. Sci. U.S.A. 71, 894-898 (1974)

15. Gall, J. G.: Free ribosomal RNA genes in the macronucleus of Tetrahymena. Proc. Nat. Acad. Sci. 71, 3078-3081 (1974)

16. Howard, A. \& S. R. PelC: Synthesis of deoxyribonucleic acid in normal and irradiated cells and its relation to chromosome breakage. Heredity, suppl. 6, 261-273 (1953)

17. Karrer, K. \& J. G. Gall: The macronuclear ribosomal DNA of Tetrahymena pyriformis is a palindrome. J. Mol. Biol. 104, 421-453 (1976)
18. LuFT, J. H.: Improvements in epoxy resin embedding methods. J. biophys. biochem. Cytol. 9, 409-414 (1961)

19. Leick, V.: The formation of ribosomes in Tetrahymena pyriformis. Tutein and Koch, Copenhagen 1973

20. Nitsson, J. R.: Suggestive structural evidence for macronuclear "subnuclei« in Tetrahymena pyriformis GL. J. Protozool. 17, 539-548 (1970)

21. NiLsson, J. R. : An electron microscope autoradiographic study of the Tetrahymena pyriformis GL macronucleus after a short period of tritiated nucleoside labelling. C. R. Trav. Lab. Carlsberg 39, 357-373 (1973)

22. Nilsson, J. R. \& V. Leick: Nucleolar organization and ribosome formation in Tetrahymena pyriformis GL. Exp. Cell Res. 60, 361-372 (1970)

23. Nitsson, J. R. \& E. Zeuthen: Microscopical studies on the macronucleus of heat synchronized Tetrahymena pyriformis GL. C. R. Trav. Lab. Carlsberg 40, 1-18 (1974)

24. Nilsson, J. R., J. Engberg \& V. Leick: On timing of nucleolar DNA replication in Tetrahymena pyriformis GL. J. Protozool. 24, 30A31A (1977)

25. Pearlman, R. E., P. Andersson, J. Engberg \& J. R. NiLsson: Synthesis of ribosomal DNA in conjugating Tetrahymena. Exp. Cell Res. 123. 147-155 (1979)

26. ReYNold, E. S.: The use of lead citrate at high $\mathrm{pH}$ as an electron-opaque stain in electron microscopy. J. Cell Biol. 17, 208-212 (1962)

27. Plesner, P., L. Rasmussen \& E. Zeuthen: Techniques used in the study of synchronous Tetrahymena. In: Synchrony in cell division and growth, E. Zeuthen ed., Interscience Publ., New York, pp. 543-564 (1964)

28. Zeuthen, E.: Synchrony in Tetrahymena by heat shocks spaced a normal cell generation apart. Exp. Cell Res. 68, 49-60 (1971) 